\title{
Spontaneous Ag-Nanoparticle Growth at Single-Walled Carbon Nanotube Defect Sites: A Tool for In Situ Generation of SERS Substrate
}

\author{
Jason Maley, ${ }^{1}$ Gabriele Schatte, ${ }^{1}$ Jian Yang, ${ }^{2}$ and R. Sammynaiken ${ }^{1}$ \\ ${ }^{1}$ Saskatchewan Structural Sciences Centre, University of Saskatchewan, 110 Science Place, Saskatoon, SK, Canada S7N 5C9 \\ ${ }^{2}$ College of Pharmacy, University of Saskatchewan, 110 Science Place, Saskatoon, SK, Canada S7N 5C9
}

Correspondence should be addressed to Jason Maley, j.maley@usask.ca and R. Sammynaiken, r.sammynaiken@usask.ca

Received 31 March 2011; Accepted 4 July 2011

Academic Editor: A. M. Rao

Copyright (C) 2011 Jason Maley et al. This is an open access article distributed under the Creative Commons Attribution License, which permits unrestricted use, distribution, and reproduction in any medium, provided the original work is properly cited.

\begin{abstract}
Silver nanoparticles were spontaneously formed on pristine and oxidized single-wall nanotubes. Nanoparticles were observed on carbon nanotubes with AFM, and the presence of Ag nanoparticles were confirmed by ESR experiments. Raman spectroscopy of the Ag-treated carbon nanotubes had a $4-10 \mathrm{X}$ enhancement of intensity compared to untreated carbon nanotubes. Ag nanoparticles formed at defect sites on the CNT surface, where free electrons located at the defect sites reduced $\mathrm{Ag}^{+}$to $\mathrm{Ag}$. $\mathrm{A}$ mechanism for the propagation of the nanoparticles is through a continual negative charge generation on the nanoparticle by electron transfer from doublet oxygen $\left(\mathrm{O}_{2}{ }^{-}\right)$.
\end{abstract}

\section{Introduction}

Since the discovery of carbon nanotubes was first published in 1991, their unique chemical and physical properties have since attracted interest in a wide spectrum of fields, including materials science, engineering, physical sciences, and medical/health sciences [1-5]. In its simplest form, single-walled carbon nanotubes (SWCNTs) are composed of a single graphene layer rolled into a cylindrical shape, having dimensions of $0.4-1 \mathrm{~nm}$ diameter and lengths on the order of $10^{3} \mathrm{~nm}$. Multi walled carbon nanotubes (MWCNTs), on the other hand, are composed of an array of concentric cylinders with diameters up to $50 \mathrm{~nm}$. In addition, the orientation of the graphitic rings along the tubular surface result in the CNTs exhibiting metallic or semiconducting properties [6].

Similar to CNTs, metal nanoparticles have also generated interest, especially in regards to sensors, catalysis, and fuel cell research. Integrating nanoparticles with CNTs is an attractive feature that has potential application in catalysis, sensors, and fuel cells due to the enhanced dispersion and performance [7-9]. There are many strategies for incorporating metal nanoparticles onto CNT surfaces. One of the most straight forward methods is vapor deposition of a metal layer onto the CNT surface [10]. However, this method requires the deposition of the CNTs onto a substrate, followed by depositing a metal film under vacuum. Electrodepositing Ag through electrolysis reduction $[11,12]$, or through a $\eta^{2}-$ coordination, where a $\mathrm{Sn}^{2+}$-activated surface reduces $\mathrm{Ag}^{+}$ onto the CNT surface [13]. Irradiating CNTs with $\gamma$-rays in the presence of $\mathrm{Ag}^{+}$as well as some type of hydrophilic polymer has also produced Ag-decorated CNTs, presumably through the attachment of the polymer onto the CNT surface [14-16].

Here, we report the spontaneous formation of $\mathrm{Ag}$ nanoparticles onto freshly sonicated SWCNT surfaces. Raman spectroscopy measurements revealed signal enhancement caused by CNT/Ag nanoparticle interaction, and the presence of Ag nanoparticles on the SWCNT surface is supported by atomic force microscopy (AFM) measurements as well as electron spin resonance (ESR) spectroscopy. A mechanism for the formation of Ag nanoparticles on SWCNT defect sites is proposed.

\section{Experimental}

2.1. Chemicals. Unless otherwise stated, all chemicals were reagent grade and used as received. SWCNT and were 


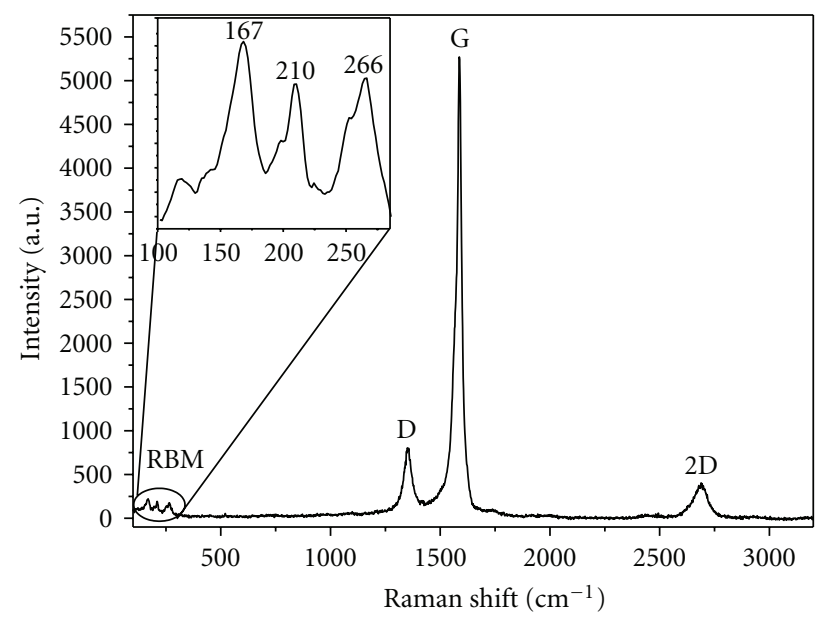

(a)

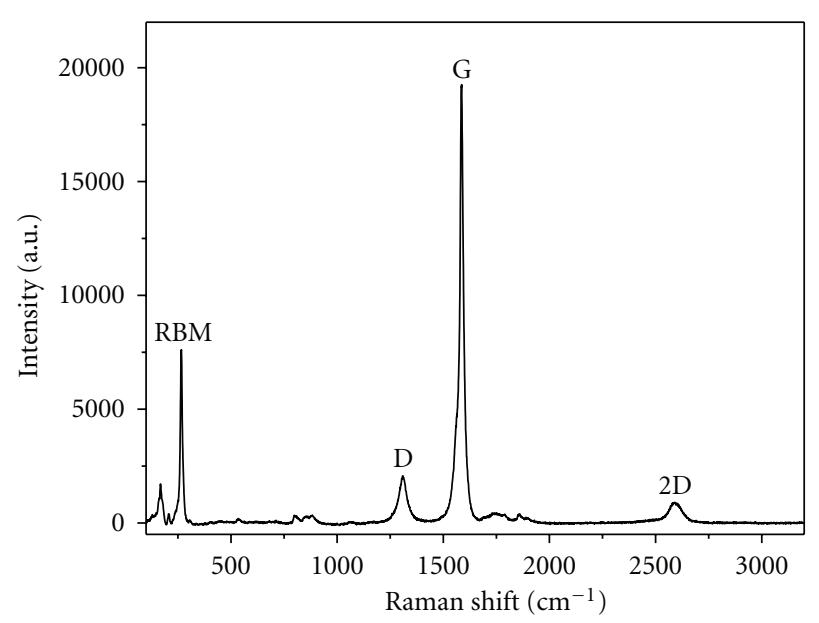

(b)

FIgURE 1: (a) Raman spectra of SWCNT using (a) $2.41 \mathrm{eVand}$ (b) $1.58 \mathrm{eV}$ laser excitation. Significant peaks are labeled. The laser power measured at the sample was $0.1 \mathrm{~mW}$ for (a) and $0.4 \mathrm{~mW}$ for (b).

purchased from Cheap Tubes (Brattleboro, VT). All water used in experiments was Millipore grade $(18.2 \mathrm{M} \Omega \mathrm{cm})$.

2.2. Raman Spectroscopy. Raman spectroscopy measurements were carried out on a Renishaw InVia Reflex Raman microscope using a solid state laser diode (Renishaw) operating at $785 \mathrm{~nm}$, and a 1200 lines $/ \mathrm{mm}$ grating, or a $\mathrm{Ar}^{+}$ laser (Spectra Physics Model 153-M42-010) operating at $514.5 \mathrm{~nm}$ and a 1800 line $/ \mathrm{mm}$ grating. The microscope was focused onto the sample using a Leica 50X N PLAN objective $(\mathrm{NA}=0.75)$, and the backscattered Raman signals were collected with a Peltier-cooled CCD detector. The instrument was operated in the line focus mode with a $10 \mathrm{~s}$ detector exposure time. The instrument calibration was verified using an internal Si sample, which was measured at $520 \mathrm{~cm}^{-1}$.

2.3. Atomic Force Microscopy. AFM measurements were carried out on an Agilent 4500 AFM (Agilent Technologies, Chandler, Ariz USA) operating in intermittent contact mode. A silicon cantilever (Nanoscience Instruments Inc., Tempe, $\mathrm{Az}$ ) with a curvature radius of approximately $10 \mathrm{~nm}$ was used for AFM measurements. Its specifications include a force constant of approximately $48 \mathrm{~N} / \mathrm{m}$, and a resonant frequency of approximately $190 \mathrm{kHz}$. All measurements were taken with the ratio of the set-point oscillation amplitude to free air oscillation amplitude of 0.80 and a resonance amplitude in the range of $1-1.5 \mathrm{~V}$. In addition, all measurements were performed at ambient conditions with the instrument mounted in a vibration isolation system. The scan rate was $0.5-1 \mathrm{~Hz}$ (256 pixels per line) for all images. Height and width measurements from resulting were obtained using SPIP V5.1.5. (Image Metrology, Denmark).

CNT samples were prepared by dissolving the samples in $\mathrm{EtOH}$ to a concentration in the range of $10^{2} \mu \mathrm{g} / \mathrm{mL}$, and sonicated for approximately $1 \mathrm{~min}$. Approximately $25 \mu \mathrm{L}$ of solution was dropped onto freshly cleaved mica, incubated for $5 \mathrm{~min}$, and gently dried with nitrogen gas.
2.4. Electron Spin Resonance Spectroscopy. ESR spectra were recorded on a Bruker EMX ESR spectrometer equipped with an Oxford cryostat ESR900 operating at $6 \mathrm{~K}$. Typical operating parameters were as follows: microwave frequency $9.388 \mathrm{GHz}$, microwave power $2.00 \mathrm{~mW}$, centre field $3349.88 \mathrm{G}$, sweep widths of 6000.0 and $200.0 \mathrm{G}$, conversion time $163.84 \mathrm{~ms}$, time constant $81.92 \mathrm{~ms}$, sweep time $167.77 \mathrm{~s}$, modulation frequency $100 \mathrm{kHz}$, modulation amplitude $1.0 \mathrm{G}$, receiver gain $3.56 \times 10^{4}$.

\section{Results and Discussion}

Raman spectroscopy provides rich information for CNT characterization. Structural and electronic properties of CNTs can be evaluated by careful interpretation of the Raman spectrum [6]. The Raman spectra of both pristine SWCNT powder are shown in Figure 1. The bands associated with the radial breathing mode transitions are located at low frequencies, and a useful equation can be used to estimate the diameter $\left(d_{t}\right)$ of the CNTs

$$
d_{t}=\frac{A}{\omega_{\mathrm{RBM}}-B},
$$

where $\omega_{\mathrm{RBM}}$ is the RBM band for the nanotube in resonance with the excitation laser line, $A$ and $B$ are constants determined experimentally. For SWCNT bundles, $A$ and $B$ values of $234 \mathrm{~nm} \mathrm{~cm}^{-1}$ and $10 \mathrm{~cm}^{-1} \mathrm{~nm}$, respectively, have been determined [17]. By using (1), $d_{t}$ for the SWCNT used in this study ranged from 0.8 to $1.5 \mathrm{~nm}$.

The lineshape of the $G$ band located at approximately $1590 \mathrm{~cm}^{-1}$ indicates that the SWCNTs used in this study are semiconducting SWCNTs [6]. The G band is composed of 2 main bands: (1) $\mathrm{G}^{+}$band located around $1590 \mathrm{~cm}^{-1}$ and associated with $\mathrm{C}$ atom vibrations along the nanotube axis and (2) $\mathrm{G}^{-}$band located at approximately $1560 \mathrm{~cm}^{-1}$ and associated with $\mathrm{C}$ atom vibrations along the circumferential direction. The lineshape of the $\mathrm{G}^{-}$band for metallic SWCNTs 
TABLE 1: Analysis of G and D Raman bands for untreated SWCNT and Ag-treated SWCNT for $1.58 \mathrm{eV}$.

\begin{tabular}{|c|c|c|c|c|c|c|}
\hline \multirow{2}{*}{ Raman band } & \multicolumn{3}{|c|}{ Untreated SWCNT } & \multicolumn{3}{|c|}{ Ag-treated SWCNT } \\
\hline & Raman shift $\left(\mathrm{cm}^{-1}\right)$ & Peak width $\left(\mathrm{cm}^{-1}\right)$ & Intensity & Raman shift $\left(\mathrm{cm}^{-1}\right)$ & Peak width $\left(\mathrm{cm}^{-1}\right)$ & Intensity \\
\hline $\mathrm{G}^{+}$ & 1587 & 19 & 18370 & 1586 & 14 & 75780 \\
\hline $\mathrm{G}^{-}$ & 1559 & 26 & 2444 & 1568 & 68 & 20263 \\
\hline $\mathrm{D}$ & 1309 & 47 & 1957 & 1306 & 40 & 3408 \\
\hline
\end{tabular}

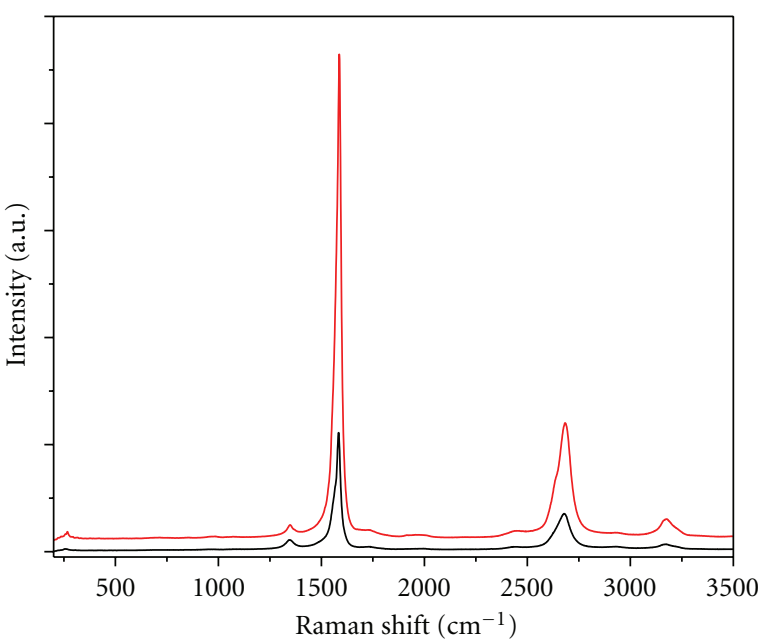

- Ag/SWCNT

- SWCNT

(a)

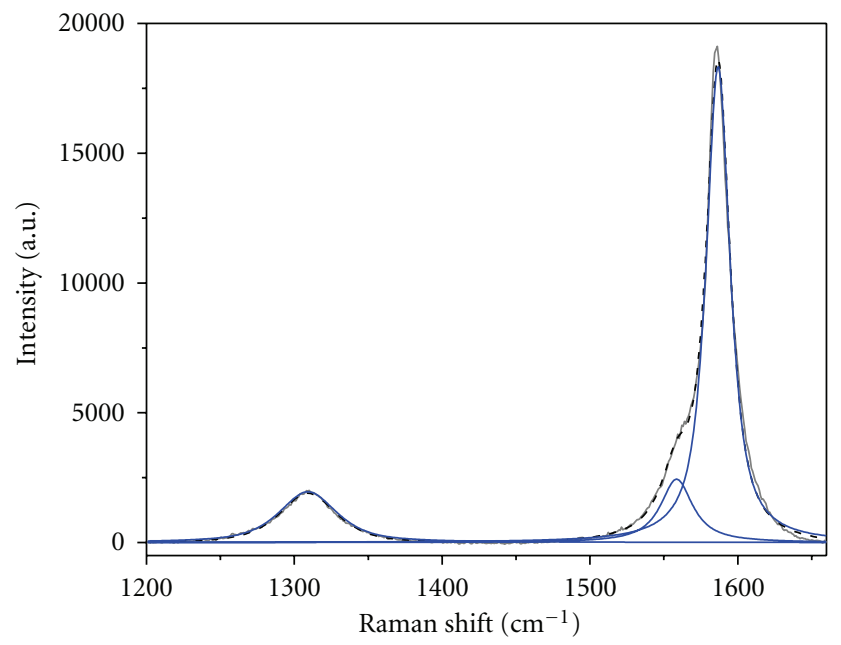

(c)

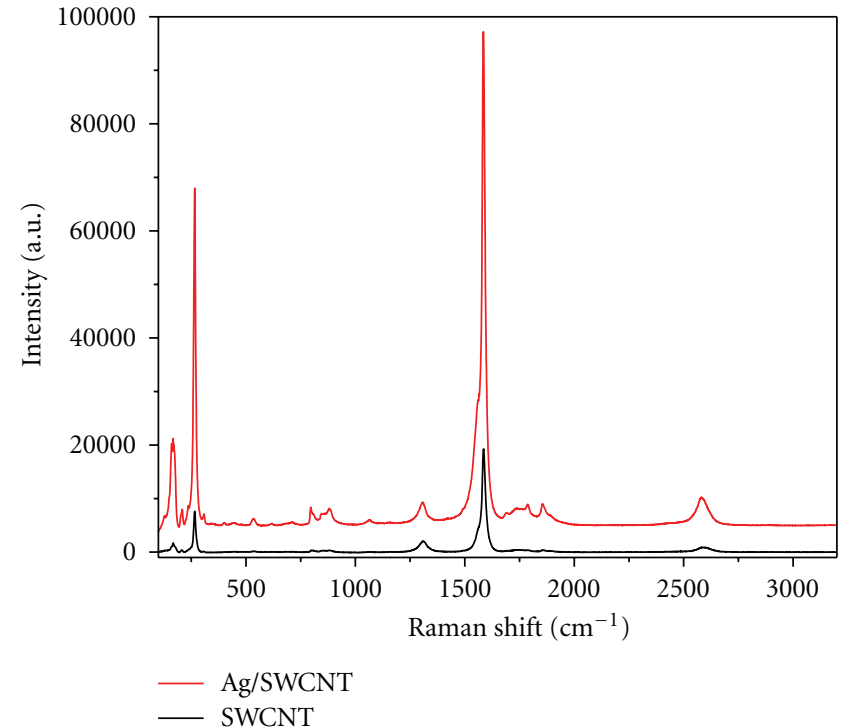

(b)

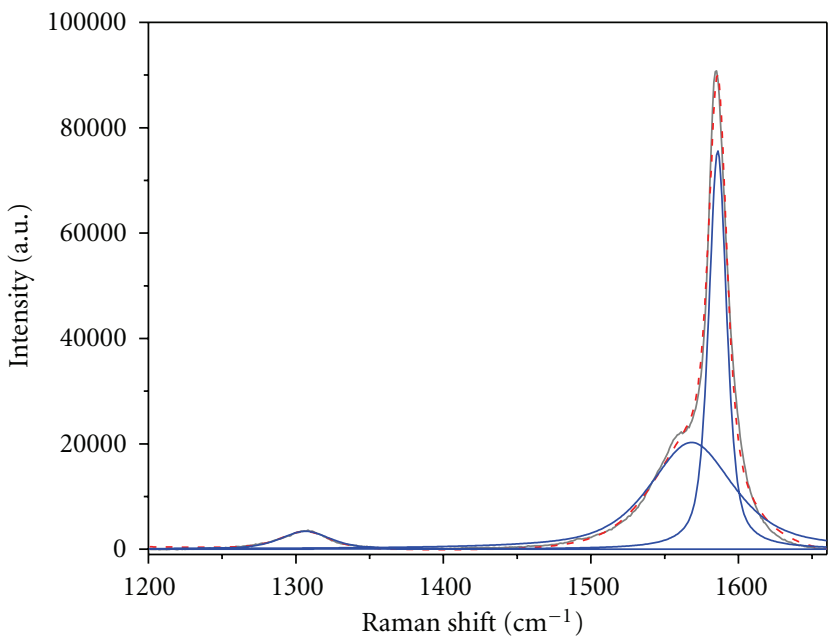

(d)

FIGURE 2: Raman spectra untreated SWCNT and Ag-treated SWCNT using (a) $2.41 \mathrm{eV}$ (b) $1.58 \mathrm{eV}$ laser excitation. The laser power measured at the sample was $1 \mathrm{~mW}$ for (a) and $0.4 \mathrm{~mW}$ for (b). Curve fitting of D and G bands for (c) SWCNT and (d) Ag treated SWCNT.

has a Breit-Wigner-Fano lineshape, and its intensity is similar to the $\mathrm{G}^{+}$band [18]. The $\mathrm{D}$ band is a 2 nd order phonon mode that is sensitive to disorder-induced effects on the nanotube sidewall, and the 2D band is an overtone of the $\mathrm{D}$ band.

Sonication and refluxing the SWCNTs are known to break the CNTs, thus increasing the number of defects on the CNT [19]. Freshly sonicated SWCNTs were exposed to $1 \mathrm{mM}$ solution of $\mathrm{AgNO}_{3}$, centrifuged, and dried. The corresponding Raman spectra of the Ag-treated SWCNT and untreated SWCNT are shown in Figure 2 and fitting results of the more notable bands are summarized in Table 1. In general, there are a few differences associated with the Ag-treated SWCNT compared to the SWCNT. In Figure 2(a), the $I_{\mathrm{G}} / I_{\mathrm{D}}$ ratio increased from about 10.1 for SWCNT to approximately 30.4 for Ag-treated SWCNT. Similarly, approximately 3 times decrease in the D-band 
intensity (Figure 2(b)) was also observed for Raman data acquired with a $1.58 \mathrm{eV}$ laser excitation line. Intercalation of acceptor/donor groups typically increases the intensity and linewidth of the $\mathrm{D}$ band, as well as an upshift/downshift of the $\mathrm{G}^{+}$band $[20,21]$. The observed decrease in the D-band intensity and the essentially constant position of the $\mathrm{G}^{+}$band indicate that the Ag treatment induces any substitutional effects along the CNT surface. In addition to a slight downshift $\left(3 \mathrm{~cm}^{-1}\right)$ and decrease in peak width $\left(47 \mathrm{~cm}^{-1}\right.$ for SWCNT to $40 \mathrm{~cm}^{-1}$ ) for Ag-treated SWCNT compared to the SWCNT, the decrease in D-band intensity and lineshape, as well as the slight downshift upon Ag-treatment indicates some type of interaction occurring between the $\mathrm{Ag}$ and disorder regions located on the SWCNT surface. Also, the $\mathrm{G}^{-}$peak upshifts by approximately $10 \mathrm{~cm}^{-1}$. It has been previously reported that induced strain to SWCNT bundles causes an upshift in the $\mathrm{G}^{-}$band [22] .

The most significant feature observed was the 5-10 times increase in Raman intensity within several spots of the Ag-treated SWCNT. This increase in Raman intensity indicates the presence of Ag nanoparticles creating a Surface Enhanced Raman Spectroscopy (SERS) hot spot, where the differences in the Raman spectra are due to a Agnanoparticle interaction with the SWCNT. Ag-nanoparticles on the surface of SWCNT induce strain on the attachment point with a possible small charge transfer to the SWCNT. Signal enhancement from Ag nanoparticle in contact with CNT surfaces has been well documented. For instance, Kumar and coworkers measured Raman spectra individual SWCNT grown on Si both before and after Ag deposition and found that the signal intensity increased 9-335 times (corresponding to SERS enhancement factors in the range of 3340-134000) [10]. Chen and co-workers electrodeposited Ag onto SWCNTs, and found the relative intensity of the G band to increase on the order of 2-14 times for 514.5 and $785 \mathrm{~nm}$ laser excitation sources [11].

It is well known that Ag nanoparticles can be formed by thermal decomposition, or the addition of a reducing agent as shown in the following equations

$$
\begin{aligned}
& \operatorname{AgNO}_{3}(\mathrm{aq}) \stackrel{444 \circ \mathrm{C}}{\longrightarrow} \mathrm{Ag}(\mathrm{s})+\mathrm{NO}_{2}(\mathrm{~g})+\frac{1}{2} \mathrm{O}_{2}(\mathrm{~g}) \\
& \mathrm{AgNO}_{3}(\mathrm{aq})+\mathrm{NaBH}_{4}(\mathrm{aq}) \\
& \longrightarrow \mathrm{Ag}(\mathrm{s})+\frac{1}{2} \mathrm{H}_{2}(\mathrm{~g})+\frac{1}{2} \mathrm{~B}_{2} \mathrm{H}_{6}(\mathrm{aq})+\mathrm{NaNO}_{3}(\mathrm{aq})
\end{aligned}
$$

However, this is simply not the case here, as there was no reducing agent present in solution, and the laser power on the Raman spectrometer was quite low. Also, the laser excitation was not high enough to induce thermal decomposition of any residual Ag salt.

Figure 3 shows AFM topography images of SWCNT and Ag-treated SWCNT. The SWCNT topography image shows isolated SWCNT with heights in the range of $0.8-$ $1.0 \mathrm{~nm}$, as well as SWCNT in a bundled form ( $>2 \mathrm{~nm}$ height). On the other hand, there are instances of the appearance of nanoparticles attached to SWCNTs for the Ag-treated samples. The nanoparticles attached to both individual and bundled SWCNTs (Figures 3(b)-3(d)) and appeared at mainly the end and along the middle of the CNT walls, presumably at defect sites. The nanoparticle heights were typically in the range of 5-6 $\mathrm{nm}$.

Ag nanoclusters that are not large enough to form conduction bands are still paramagnetic. ESR spectroscopy is extremely sensitive to paramagnetic species and is ideal for detecting disperse and dilute quantities of paramagnetic species. It is ideal to verify that the particles observed in the AFM are not amorphous carbon materials but that they are $\mathrm{Ag}$ nanoparticles. Figure 4 shows the ESR spectrum of $\mathrm{Ag}$ nanoparticles at $6 \mathrm{~K}$. It is a line centered around 3350 Gauss or $g=2.0023$. The $g$ value is the same as reported for Agnanoparticles by Mitrikas and co-workers, but the line width is significantly larger. Mitrikas observed quantum effects and a decrease in line width as the size of particles increase within the range of 3-10 $\mathrm{nm} \mathrm{[23].} \mathrm{The} \mathrm{observed} \mathrm{linewidth}$ of 40 Gauss and no power saturation at several milliwatts are different from other ESR studies. The observed SERS is a clear indication that there is interaction between the SWCNT and the Ag nanoparticle. The interaction allows for faster relaxation, thus accounting for the increased linewidth and lack of power saturation. Noninteracting or isolated Ag nanoparticles would be expected to powersaturate very easily due to long relaxation and resulting sharp lines $[23,24]$.

Formation of Ag nanoparticles in situ has been accomplished by other methods, including $\gamma$-irradiation, sonochemistry, and electroless reduction mechanisms. It is well known that $\gamma$-irradiation of water produces solvated electrons $\left(\mathrm{e}_{\text {solv }}^{-}\right)$, as well as $\mathrm{H}^{\bullet}$ and $\mathrm{OH}^{\bullet}$ radicals. Metal ions will be reduced by $\mathrm{e}_{\text {solv }}^{-}$, and the addition of polymers such as PVA will be oxidized, and the corresponding polymer radical have been reported to interact with the CNT surface. The PVA radical has been shown to also reduce $\mathrm{Ag}^{+}$to form nanoclusters of Ag on the surface of MWCNTs [25]. Sonicating water also produces $\mathrm{H}^{\bullet}$ and $\mathrm{OH}^{\bullet}$ radicals, which again can reduce $\mathrm{Ag}^{+}$to nanoclusters [26]. In a previous study, we reported spontaneous $\mathrm{Ag}$ nanoclusters deposit onto porous $\mathrm{Si}$ by both a hydride and a negative charge mechanism through unpaired electrons located on the surface of porous Si $[27,28]$. With the exception of the hydride, we propose a similar mechanism for the formation of $\mathrm{Ag}$ nanoparticles on the surface of SWCNT. Freshly created defects are created by sonication of the SWCNTs. These defects have an affinity for free surface electrons which can reduce aqueous $\mathrm{Ag}^{+}$onto the surface of the CNT. Propagation of the Ag nanoparticle is then achieved by a series of steps

$$
\begin{aligned}
{[\mathrm{CNT}] \mathrm{e}^{-}+\mathrm{Ag}^{+}(\mathrm{aq}) \longrightarrow } & {[\mathrm{CNT}]: \mathrm{Ag}(\mathrm{s})+\mathrm{H}^{+}(\mathrm{aq}) } \\
& +\mathrm{OH}^{-}(\mathrm{aq}), \\
2 \mathrm{OH}^{-}(\mathrm{aq})+\mathrm{O}_{2}(\mathrm{~g}) \longrightarrow \mathrm{H}_{2}(\mathrm{~g})+2 \mathrm{O}_{2}{ }^{-}(\mathrm{aq}), & \longrightarrow[\mathrm{CNT}]: \mathrm{Ag}^{-}+\mathrm{O}_{2}(\mathrm{~g}) .
\end{aligned}
$$

The silver cluster is not floating in solution. It is anchored to the CNT: and builds with time and concentration of $\mathrm{Ag}^{+}$

$$
\begin{aligned}
{[\mathrm{CNT}]: \mathrm{Ag}^{-}+\mathrm{Ag}^{+}(\mathrm{aq}) \longrightarrow } & {[\mathrm{CNT}] \mathrm{Ag}_{2}+\mathrm{H}^{+}(\mathrm{aq}) } \\
& +\mathrm{OH}^{-}(\mathrm{aq}) .
\end{aligned}
$$




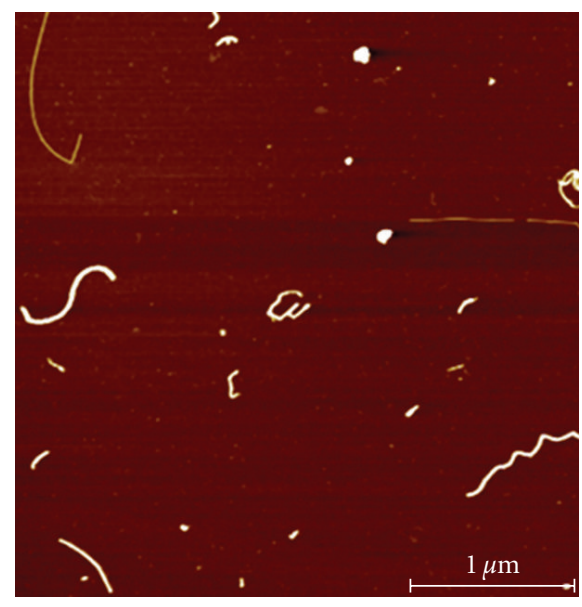

(a)

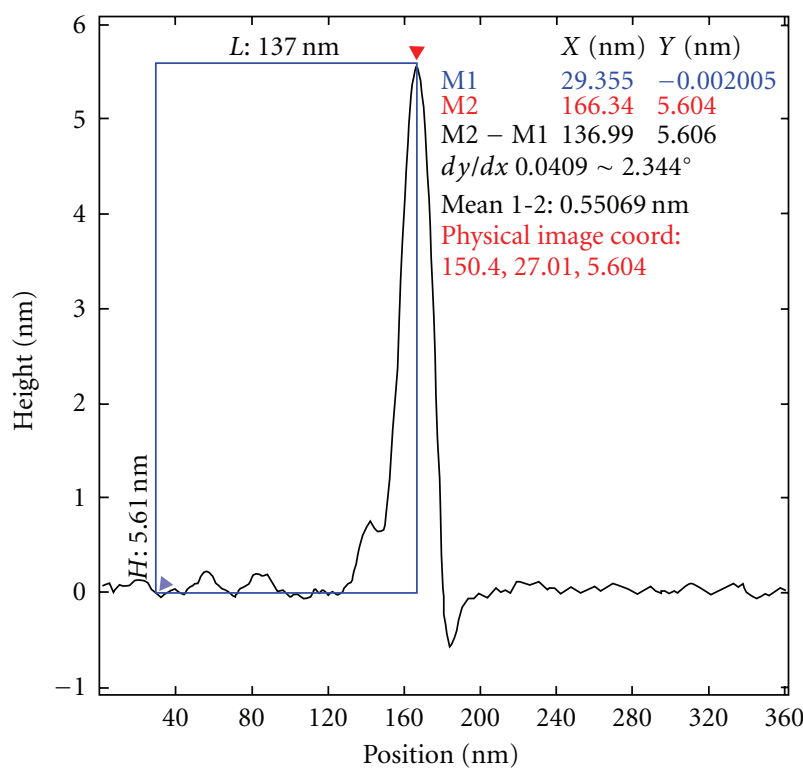

(c)

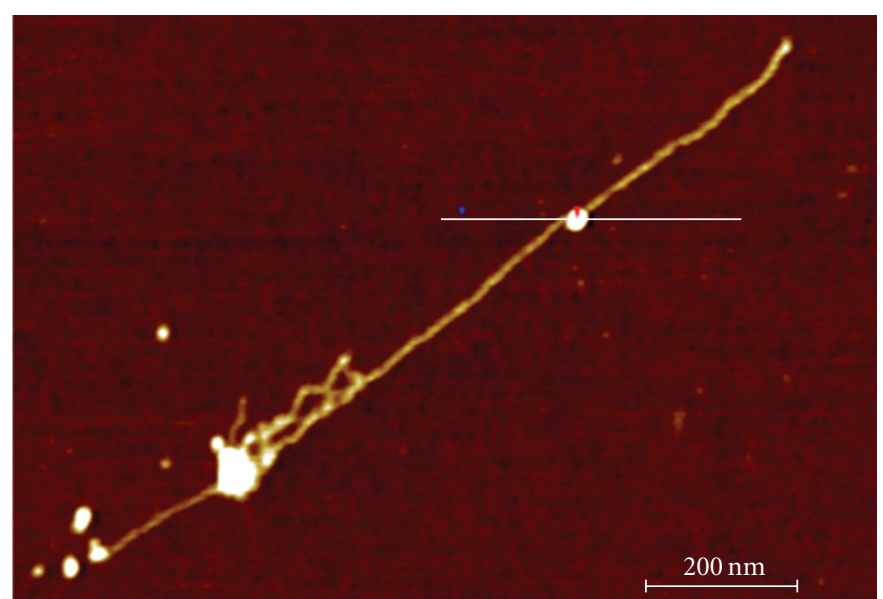

(b)

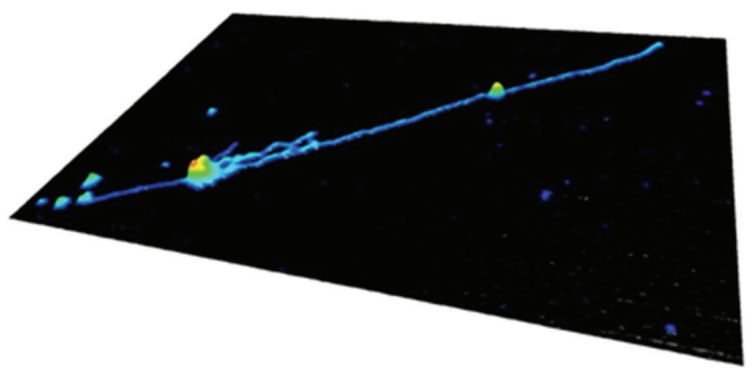

(d)

FIGURE 3: AFM topography images of (a) SWCNT and (b) Ag-treated SWCNT. SWCNT sample shows the presence of individual SWCNT and bundled SWCNTs. (c) Line profile from (b) of Ag nanoparticle on the surface of SWCNT. (d) 3D topography image of (b).

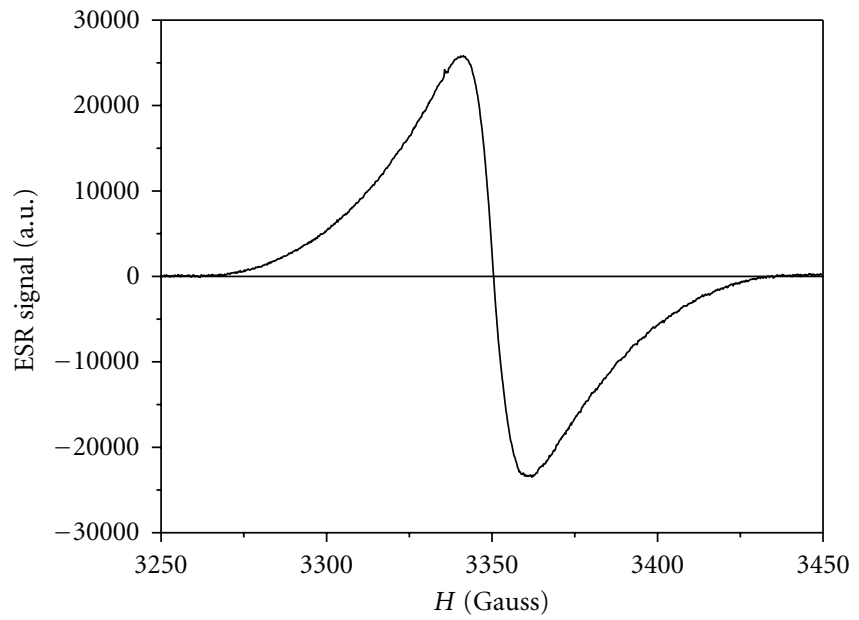

(a)

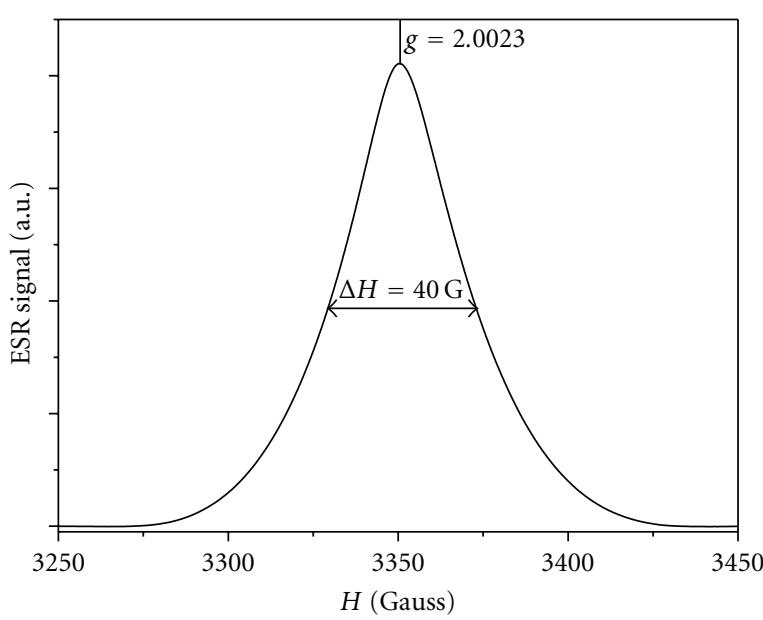

(b)

FIgURE 4: ESR spectrum of Ag-treated SWCNT taken at $6 \mathrm{~K}$. (a) First derivative (b) absorption. 
The key to forming silver nanoparticles on the CNT surface relies on the continual regeneration of negative charge on the silver cluster through the formation of doublet oxygen $\left(\mathrm{O}_{2}{ }^{-}\right)$by charge transfer from a hydroxide ion to dissolved triplet oxygen $\left(\mathrm{O}_{2}\right)$. The formation of anionic Ag clusters and dioxygen species has been previously reported in gas phase reactions [29]. Evidence for the generation of the doublet state oxygen has been conducted using nanomaterial and the spin trap DMPO in the presence of oxygen [30]. A single negative charge on the defect site will only result in the deposition of a single silver atom. However, replenishing the negative charge on the Ag surface allows for larger clusters to be formed. The size of clusters depends on the concentration of $\mathrm{AgNO}_{3}$ used [27].

SERS requires materials to be in physical contact with SERS active metals, like Ag. In addition, signal enhancement will be controlled by size and shape of the Ag nanoparticles. Other metal deposition strategies onto CNT surfaces have been reported with SERS enhancement $[10,11]$. The SERS enhancement we observed was not uniform throughout the sample, and we found local "hot spots" within the CNT sample. However, the possibility of using this method for an in situ signal enhancement for not only CNTs reported here, but for other nanomaterials in very intriguing.

\section{Conclusions}

Aqueous $\mathrm{Ag}^{+}$is reduced by the negative charge of the surface defect of SWCNT, and the process is propagated by the generation of doublet state oxygen anion. A simple novel method for spontaneous and in situ Ag-nanoparticle formation has been described. This method has potential application for spontaneous creation of hot spots for Raman signal enhancement in materials and health science.

\section{Acknowledgments}

Raman microscopy, AFM, and ESR experiments were conducted at the Saskatchewan Structural Sciences Centre which is supported by the University of Saskatchewan. The authors also thank the Canadian Breast Cancer Foundation for support.

\section{References}

[1] M. S. Dresselhaus, G. Dresselhaus, J. C. Charlier, and E. Hernández, "Electronic, thermal and mechanical properties of carbon nanotubes," Philosophical Transactions of the Royal Society of London A, vol. 362, no. 1823, pp. 2065-2098, 2004.

[2] B. S. Harrison and A. Atala, "Carbon nanotube applications for tissue engineering," Biomaterials, vol. 28, no. 2, pp. 344353, 2007.

[3] W. Hoenlein, F. Kreupl, G. S. Duesberg et al., "Carbon nanotube applications in microelectronics," IEEE Transactions on Components and Packaging Technologies, vol. 27, no. 4, pp. 629-634, 2004.
[4] L. Santiago-Rodríguez, G. Sánchez-Pomales, and C. R. Cabrera, "DNA-functionalized carbon nanotubes: Synthesis, selfassembly, and applications," Israel Journal of Chemistry, vol. 50, no. 3, pp. 277-290, 2010.

[5] H. C. Wu, X. Chang, L. Liu, F. Zhao, and Y. Zhao, "Chemistry of carbon nanotubes in biomedical applications," Journal of Materials Chemistry, vol. 20, no. 6, pp. 1036-1052, 2010.

[6] M. S. Dresselhaus, G. Dresselhaus, R. Saito, and A. Jorio, "Raman spectroscopy of carbon nanotubes," Physics Reports, vol. 409, no. 2, pp. 47-99, 2005.

[7] P. Serp, M. Corrias, and P. Kalck, "Carbon nanotubes and nanofibers in catalysis," Applied Catalysis A, vol. 253, no. 2, pp. 337-358, 2003.

[8] B. Louis et al., "Advances in the use of carbon nanomaterials in catalysis," Ordered Porous Solids, pp. 621-649, 2009.

[9] J. Nakamura, "Novel support materials for fuel cell catalysts," Springer Series in Materials Science, pp. 185-197, American Chemical Society (ACS), 2011.

[10] R. Kumar, H. Zhou, and S. B. Cronin, "Surface-enhanced Raman spectroscopy and correlated scanning electron microscopy of individual carbon nanotubes," Applied Physics Letters, vol. 91, no. 22, Article ID 223105, pp. 1-3, 2007.

[11] Y. C. Chen, R. J. Young, J. V. Macpherson, and N. R. Wilson, "Single-walled carbon nanotube networks decorated with silver nanoparticles: A novel graded SERS substrate," Journal of Physical Chemistry C, vol. 111, no. 44, pp. 16167-16173, 2007.

[12] Y. Qian, S. Huang, F. Gao, Q. Cai, L. Zhang, and W. Hu, "Superlong-oriented single-walled carbon nanotube arrays on substrate with low percentage of metallic structure," Journal of Physical Chemistry C, vol. 113, no. 17, pp. 6983-6988, 2009.

[13] S. K. Choi, K. Y. Chun, and S. B. Lee, "Selective decoration of silver nanoparticles on the defect sites of single-walled carbon nanotubes," Diamond and Related Materials, vol. 18, no. 4, pp. 637-641, 2009.

[14] J. Cveticanin, A. Krkljes, Z. Kacarevic-Popovic et al., "Functionalization of carbon nanotubes with silver clusters," Applied Surface Science, vol. 256, no. 23, pp. 7048-7055, 2010.

[15] K. A. Dubey, C. V. Chaudhari, R. Rao, Y. K. Bhardwaj, N. K. Goel, and S. Sabharwal, "Radiation processing and characterization of poly(vinyl alcohol) nano-compositespart 1: nano-particulate filler tuned crosslinking behavior," Journal of Applied Polymer Science, vol. 118, no. 6, pp. 34903498, 2010.

[16] S. D. Oh, B. K. So, S. H. Choi et al., "Dispersing of Ag, Pd, and Pt-Ru alloy nanoparticles on single-walled carbon nanotubes by $\gamma$-irradiation," Materials Letters, vol. 59, no. 10, pp. 11211124, 2005.

[17] M. Milnera, J. Kürti, M. Hulman, and H. Kuzmany, "Periodic resonance excitation and intertube interaction from quasicontinuous distributed helicities in single-wall carbon nanotubes," Physical Review Letters, vol. 84, no. 6, pp. 13241327, 2000.

[18] S. D. M. Brown, A. Jorio, P. Corio et al., "Origin of the BreitWigner-Fano lineshape of the tangential G-band feature of metallic carbon nanotubes," Physical Review B, vol. 63, no. 15, pp. 1-8, 2001.

[19] C. G. Salzmann, S. A. Llewellyn, G. Tobias, M. A. H. Ward, Y. Huh, and M. L. H. Green, "The role of carboxylated carbonaceous fragments in the functionalization and spectroscopy of a single-walled carbon-nanotube material," Advanced Materials, vol. 19, no. 6, pp. 883-887, 2007.

[20] S. B. Fagan, A. G. S. Filho, J. M. Filho, P. Corio, and M. S. Dresselhaus, "Electronic properties of Ag- and $\mathrm{CrO} 3$-filled 
single-wall carbon nanotubes," Chemical Physics Letters, vol. 406, no. 1-3, pp. 54-59, 2005.

[21] M. Terrones, A. Filho, and A. Rao, "Doped carbon nanotubes: synthesis, characterization and applications," in Carbon Nanotubes, pp. 531-566, Springer, Berlin, Germany, 2008.

[22] R. Kumar and S. B. Cronin, "Raman scattering of carbon nanotube bundles under axial strain and strain-induced debundling," Physical Review B, vol. 75, no. 15, Article ID 155421, pp. 1-4, 2007.

[23] G. Mitrikas, C. C. Trapalis, N. Boukos, V. Psyharis, L. Astrakas, and G. Kordas, "Size distribution and EPR of silver nanoparticles in SiO2 matrix," Journal of Non-Crystalline Solids, vol. 224, no. 1, pp. 17-22, 1998.

[24] G. Mitrikas, C. C. Trapalis, and G. Kordas, "Electron spinlattice relaxation of silver nanoparticles embedded in $\mathrm{SiO} 2$ and TiO2 matrices," Journal of Chemical Physics, vol. 111, no. 17, pp. 8098-8104, 1999.

[25] M. V. Chursanova, L. P. Germash, V. O. Yukhymchuk, V. M. Dzhagan, I. A. Khodasevich, and D. Cojoc, "Optimization of porous silicon preparation technology for SERS applications," Applied Surface Science, vol. 256, no. 11, pp. 3369-3373, 2010.

[26] R. A. Salkar, P. Jeevanandam, S. T. Aruna, Y. Koltypin, and A. Gedanken, "The sonochemical preparation of amorphous silver nanoparticles," Journal of Materials Chemistry, vol. 9, no. 6, pp. 1333-1335, 1999.

[27] J. M. Maley, T. K. Sham, A. Hirose, Q. Yang, M. P. Bradley, and R. Sammynaiken, "Chemical reactions and applications of the reductive surface of porous silicon," Journal of Nanoscience and Nanotechnology, vol. 10, no. 10, pp. 6332-6339, 2010.

[28] I. Coulthard, R. Sammynaiken, S. J. Naftel, P. Zhang, and T. K. Sham, "Porous silicon: a template for the preparation of nanophase metals and bimetallic aggregates," Physica Status Solidi (A) Applied Research, vol. 182, no. 1, pp. 157-162, 2000.

[29] Y. D. Kim and G. Ganteför, "Formation of di-oxygen species on Ag anion clusters," Chemical Physics Letters, vol. 383, no. 1-2, pp. 80-83, 2004.

[30] J. Yang, G. Schatte, J. Maley, and R. Sammynaiken, "Surface Charge and Doublet Oxygen in Nanotoxicology," In preparation. 

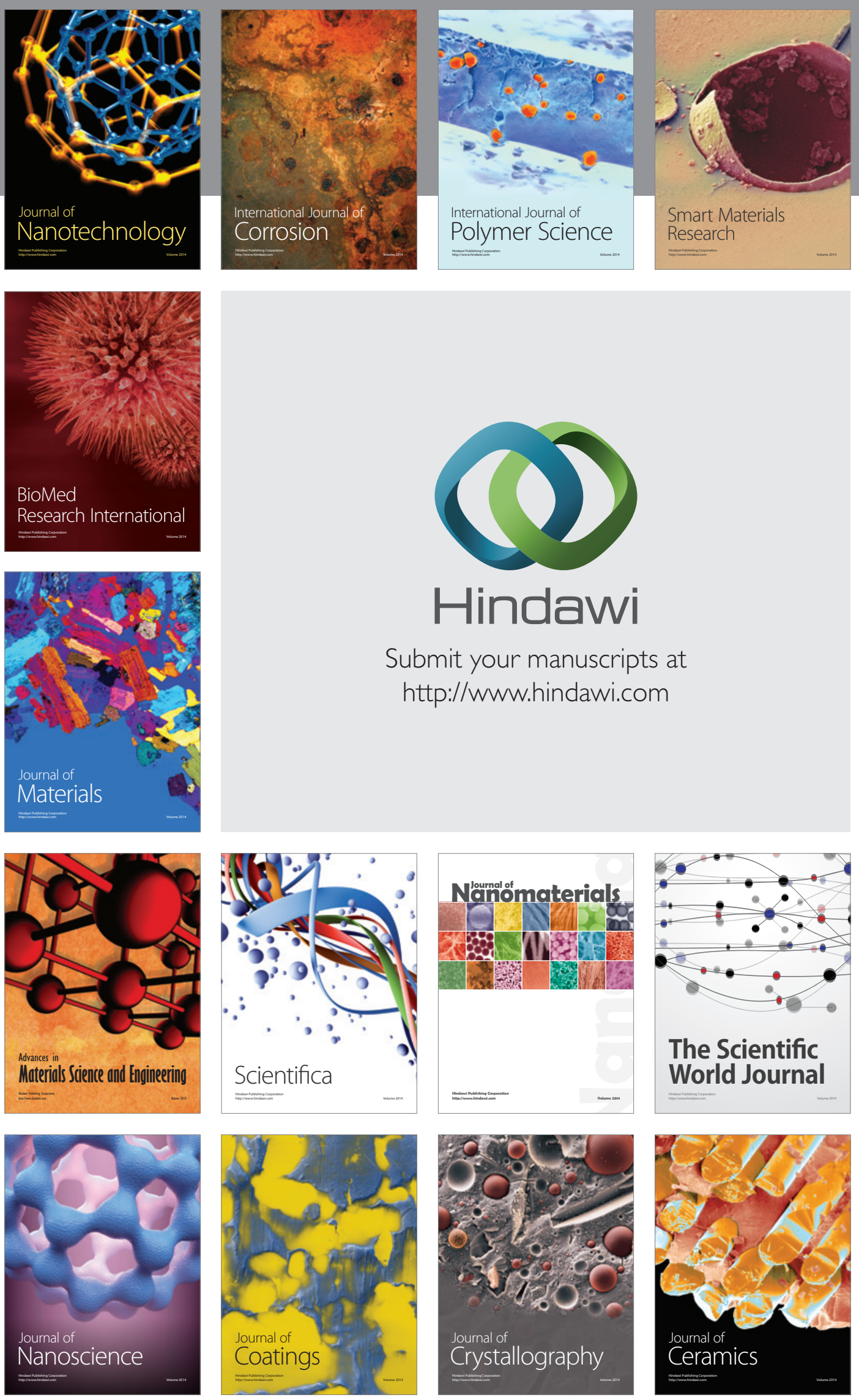

The Scientific World Journal

Submit your manuscripts at

http://www.hindawi.com

\section{World Journal}

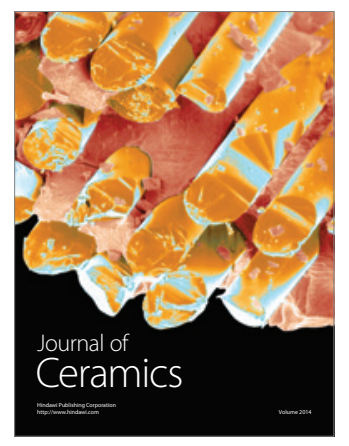

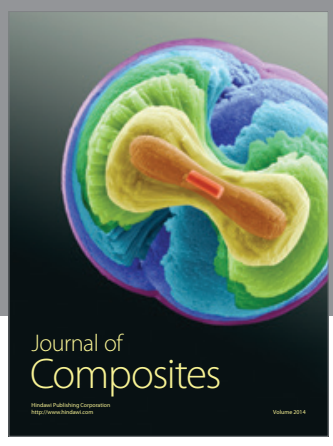
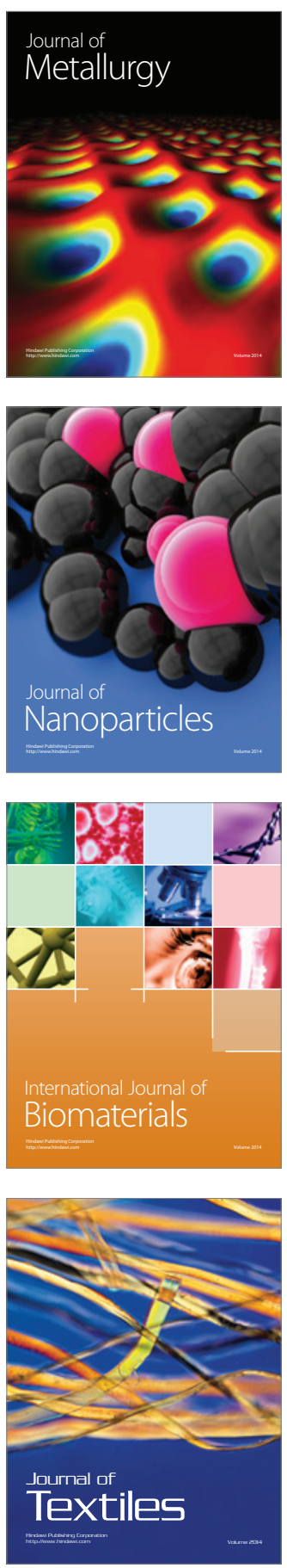